\title{
Association of tumor-infiltrating T lymphocytes with intestinal-type gastric cancer molecular subtypes and outcome
}

\author{
Naziha Mansuri ${ }^{1}$ (D) Eva-Maria Birkman ${ }^{2} \cdot$ Vanina D. Heuser $^{1} \cdot$ Minnamaija Lintunen $^{2} \cdot$ Annika Ålgars $^{3}$. \\ Jari Sundström ${ }^{2} \cdot$ Raija Ristamäki $^{3}$ - Laura Lehtinen ${ }^{1}$ - Olli Carpén ${ }^{1,4}$
}

Received: 15 May 2020 / Revised: 25 July 2020 / Accepted: 15 September 2020 / Published online: 21 September 2020

(C) The Author(s) 2020

\begin{abstract}
While host immune response is likely to be important for the prognosis of gastric cancer patients, detailed information on the T lymphocyte infiltration in different gastric cancer subtypes is lacking. Here, we studied the presence of CD3, CD8, and FOXP3 (Forkhead box p3) expressing T lymphocytes in a retrospective cohort of 190 intestinal gastric and gastroesophageal adenocarcinomas. The cancers represented four distinct molecular subtypes: Epstein-Barr virus-positive (EBV+), mismatch-repairdeficient (MMR-D), aberrant TP53, and the "other" subtype. The absolute numbers of CD3+, CD8+, and FOXP3+ T lymphocytes were analyzed in relation with these molecular subtypes and selected clinicopathological parameters. Overall, there was a large variation in the amount of infiltrating T lymphocyte in all molecular subtypes. Among the subtypes, EBV+ cancers differed from the other subtypes in increased lymphocyte infiltration and high CD8+/FOXP3+ ratio. While the TP53 aberrant subtype did not differ in the absolute amount of T lymphocyte, the ratio of CD8+/FOXP3+ and CD3+/FOXP3+ cells was highest in this subtype, possibly reflecting immunosuppression associated with genomic instability. Increased CD3+ and CD8+ T lymphocyte infiltrates were associated with better survival, and remained as independent prognostic factors in a multivariate analysis. This study is the first to investigate lymphocytic infiltration within four molecular subtypes of intestinal-type gastric cancer in a European cohort. The results provide an important addition to the current knowledge of $\mathrm{T}$ lymphocyte-dependent immune response in gastric cancer and its prognostic significance.
\end{abstract}

Keywords Gastric cancer · Molecular subtypes · Tumor infiltration · Overall survival

\section{Introduction}

Gastric cancer is the fifth most common cancer type globally, and the second most common cause of cancer death [1]. The common treatment modalities for gastric cancer patients

Naziha Mansuri

Naziha.i.mansuri@utu.fi

1 Research Center for Cancer, Infections and Immunity, Institute of Biomedicine, University of Turku, Kiinamyllynkatu, 10 20520 Turku, Finland

2 Department of Pathology, University of Turku and Turku University Hospital, Kiinamyllynkatu, 1020520 Turku, Finland

3 Department of Oncology, Turku University Hospital, Kiinamyllynkatu 4-8, 20521 Turku, Finland

4 Medicum Research Program in Systems Oncology and HUSLAB, University of Helsinki and Helsinki University Hospital, Haartmaninkatu 3, 00014 Helsinki, Finland include surgical resection and chemotherapy. Currently, the only targeted therapy is anti-HER2 treatment for cancers demonstrating HER2 amplification or polysomy [2,3]. Other treatment modalities, including immuno-oncologic treatments, are being evaluated, but it is not clear whether gastric cancer patients benefit from these treatments and on which criteria patients should be selected [4]. Unlike the traditional modalities, these therapies target the host immune system rather than the tumor. General understanding on the role of the tumor immune microenvironment is emerging, including the relationship between the host immune system and cancer. This knowledge is being used for prognostication and guiding immunotherapy, including the use of immune checkpoint inhibitors [5].

Traditionally, gastric cancer has been divided into intestinal and diffuse subtypes, based on morphological criteria [6]. Moreover, recent studies have revealed the versatile molecular background of gastric cancer. While the diffuse subtype is molecularly fairly homogenous (genomically stable), the intestinal subtype of gastric and gastroesophageal junction 
cancers can be further divided into different molecular subtypes. These subtypes include (1) Epstein-Barr virus (EBV)associated cancers, (2) mismatch-repair-deficient (MMR-D) cancers, (3) cancers with TP53 aberration, and (4) cancers lacking any of the above features ("other") [7]. The molecular subtypes are associated with different clinical features including prognosis, the TP53 mutated tumors having the worst and EBV-positive tumors the best outcome [8]. While the original molecular classification is based on genomic analysis, it is also possible to identify these subtypes by immunohistochemistry/in situ hybridization [8]. This method utilizes markers already used in clinical practice and is therefore easily adaptable to diagnostic routine.

Based on the variable immunogenic properties of gastric cancer, it is likely that the molecular subtypes elicit different levels of host immune reaction. Tumor-infiltrating lymphocytes (TILs) are considered to be a manifestation of host immune reaction against cancer cells [9]. The amount of TILs is thought to be associated with the mechanisms controlling the growth, progression, and metastasis of cancer, and they may have predictive value in the evaluation of the response to cytotoxic treatments, such as chemotherapy and radiotherapy [10]. Among these inflammatory cells, CD3 is a marker of all mature $\mathrm{T}$ lymphocytes, including different functional subsets. CD8 is a marker of cytotoxic T cells, considered to be critical for tumor surveillance [11], as they can recognize and kill tumor cells. FOXP3 is a marker of regulatory T lymphocytes (Tregs). Tregs are immunosuppressive and generally suppress or downregulate the induction and proliferation of effector $\mathrm{T}$ cells, thereby maintaining the immunological tolerance to host tissues [12]. In several cancer types, there is a strong association between the amount of tumor-infiltrating immune cells and clinical outcome. These cancer types include nonsmall cell lung cancer, colorectal cancer, ovarian cancer, breast cancer, and melanoma [13-17]. However, the role of immune cells in gastric cancer is less clear, especially in association with the different molecular subtypes.

In this study, we analyzed the immune infiltrates in intestinal-type gastric and gastroesophageal adenocarcinomas. We focused on the intestinal subtype, as its molecular heterogeneity allowed us to correlate the presence of $\mathrm{CD} 3+, \mathrm{CD} 8+$, and FOXP3+ immune cells to specific genetic and EBVinduced features. The results were analyzed in relation with the molecular subtypes and selected clinical parameters, including disease-free and overall survival.

\section{Materials and methods}

\section{Patients and tumor specimens}

The collection and characteristics of the study cohort have been previously reported [8]. In brief, a total number of 190 patients with intestinal-type gastric adenocarcinomas were selected out of a consecutive series of 244 patients diagnosed with adenocarcinoma of the stomach, gastroesophageal junction (GOJ), or distal esophagus at the Turku University Hospital between years 1993 and 2012. For confirmation of diagnosis and adequacy of material, all corresponding hematoxylin-eosin (H\&E)-stained slides were reviewed. Tumor stage was assessed according to the current WHO Classification manual [18]. The relevant clinical information was collected from the medical records. The median followup time was 125 months.

The intestinal-type cancers were classified based on the following criteria: EBER in situ hybridization-positive tumors were classified as EBV-positive, tumors showing a complete loss of nuclear reactivity of at least one of the MMR markers (MLH1, MSH2, MSH6, PMS2) were classified as MMR-D, and tumors with complete loss of or strong diffuse TP53 nuclear immunoreactivity were classified as TP53 aberrant. Tumors showing none of these alterations were classified as "other" [8]. The reporting of the study has been performed following the current recommendations [19]. The study cohort characteristics are summarized in Table 1.

\section{Tissue microarray construction}

The ngTMA (next-generation tissue microarray) construction has been described previously [20]. The TMA blocks were sectioned, stained, scanned, and uploaded into a web portal (casecenter.utu.fi) for annotation. Four individual cores $(1.0 \mathrm{~mm}$ in diameter) were collected from each tumor, two from the central area and two from the invasive front. The cores were evaluated separately for the number of $\mathrm{CD} 3+$, CD8+, and FOXP3+ T lymphocytes.

\section{Immunohistochemistry of T lymphocyte subsets}

Immunohistochemistry (IHC) reactions were performed on 4- $\mu \mathrm{m}$ paraffin sections with BenchMark XT device (Ventana/Roche). Primary antibodies were anti-CD3 (readyto-use rabbit monoclonal antibody clone 2GV6, Ventana/ Roche), anti-CD8 (rabbit monoclonal antibody clone SP57, Ventana/Roche), and anti-FOXP3 (mouse monoclonal antibody, clone 236A/E7; Abcam, Cambridge, UK at 1:200 dilution). For $\mathrm{CD} 3$ staining, the epitope retrieval was performed with $\mathrm{CC} 1$ buffer (Ventana/Roche) and the protocol used was the mild time $(30 \mathrm{~min}$ ) protocol; the antibody incubation time was 28 min at $37^{\circ} \mathrm{C}$. For $\mathrm{CD} 8$ staining, the epitope retrieval was performed with $\mathrm{CC} 1$ buffer mild time $(30 \mathrm{~min})$ protocol, the antibody incubation time was $32 \mathrm{~min}$ at $37{ }^{\circ} \mathrm{C}$, and the ultraView amplification kit (Ventana/Roche) was used with 4min incubation. For FOXP3, staining was performed according to the manufacturer's instructions. Signal detection was performed with the ultraView universal DAB Detection Kit 
Table 1 Patient characteristics of the intestinal-type esophagogastric adenocarcinomas

\begin{tabular}{|c|c|}
\hline Number of patients & $n(\%)$ \\
\hline All & 190 \\
\hline \multicolumn{2}{|c|}{ Median age at diagnosis (range) } \\
\hline & $74.4(32.9-90.9)$ \\
\hline \multicolumn{2}{|l|}{ Patient sex } \\
\hline Female & $68(35.8)$ \\
\hline Male & $122(64.2)$ \\
\hline \multicolumn{2}{|l|}{ Site of primary tumor } \\
\hline Distal esophagus & $19(10.0)$ \\
\hline $\mathrm{GOJ} /$ cardia & $60(31.6)$ \\
\hline Corpus & $52(27.4)$ \\
\hline Antrum/pylorus & $59(31.1)$ \\
\hline \multicolumn{2}{|l|}{ Tumor differentiation grade } \\
\hline Grade 1 & $17(8.9)$ \\
\hline Grade 2 & $93(48.9)$ \\
\hline Grade 3 & $80(42.1)$ \\
\hline \multicolumn{2}{|l|}{ Stage } \\
\hline I & $40(21.1)$ \\
\hline II & 79 (41.6) \\
\hline III & $61(32.1)$ \\
\hline IV & $10(5.3)$ \\
\hline \multicolumn{2}{|l|}{ TNM stage } \\
\hline $\mathrm{T} 1$ & $19(10.0)$ \\
\hline $\mathrm{T} 2$ & $30(15.8)$ \\
\hline $\mathrm{T} 3$ & $81(42.6)$ \\
\hline $\mathrm{T} 4$ & $60(31.6)$ \\
\hline No & $81(42.6)$ \\
\hline N1 & $38(20.0)$ \\
\hline $\mathrm{N} 2$ & $29(15.3)$ \\
\hline N3 & $17(8.9)$ \\
\hline $\mathrm{Nx}$ & $25(13.2)$ \\
\hline M0 & $179(94.2)$ \\
\hline M1 & $10(5.3)$ \\
\hline Mx & $1(0.5)$ \\
\hline \multicolumn{2}{|l|}{ Follow-up status } \\
\hline Alive and free of disease & $34(17.9)$ \\
\hline Alive with disease & $1(0.5)$ \\
\hline Deceased & $155(81.6)$ \\
\hline
\end{tabular}

(Ventana/Roche). CD8 and CD3 membrane staining was considered positive, while identification of FOXP3-positive T lymphocytes was based on distinct nuclear expression.

\section{Quantitative analysis of T lymphocytes}

The quantification of intratumoral $\mathrm{T}$ lymphocyte was carried out essentially as described earlier for colorectal cancer [21].
IHC-stained TMA slides were scanned and downloaded from the web portal (casecenter.utu.fi). Each spot in the TMA was divided into four areas of approximately $0.2 \mathrm{~mm}^{2}$. Images were captured using the Pannoramic Viewer software (3DHistech, Budapest, Hungary). The absolute number of positive lymphocytes for each antibody (CD3, CD8, and FOXP3) in the $0.2-\mathrm{mm}^{2}$ areas was counted using the Image J software (http://rsb.info.nih.gov/ij). Only complete tissue cores with at least $20 \%$ viable tumor tissue were included in the analysis. Evaluation of the invasive front and center of the tumors were performed separately. For the statistical analysis, the mean and median lymphocyte subset counts per tumor were used. In addition, the relative ratios of different $\mathrm{T}$ lymphocyte subsets were calculated (CD8+/FOXP3+ and $\mathrm{CD} 3+$ /FOXP3+). The quantitative analyses were carried out blinded of the clinicopathologic information.

\section{Statistical analysis}

The T lymphocyte subsets were analyzed for differences among the molecular subtypes using $\chi 2$ test or Fisher's exact test. Kaplan-Meier log-rank test was used for univariate survival analysis and Cox proportional hazards regression model for multivariate analysis. Variables that were statistically significant in univariate analysis were included in the multivariate analysis. Only recurrences $\geq 6$ months after the time of diagnosis were considered relevant for the recurrence-free survival (RFS) which was calculated from the time of diagnosis to the time of first recurrence, death of any cause, or to the last follow-up date. Overall survival (OS) was calculated from the time of diagnosis to the time of death of any cause or the last follow-up date. Statistical analyses were performed with IBM SPSS Statistics for Windows, version 240.0 (IBM Corporation, Armonk, NY). $p$ values $<0.05$ were considered statistically significant.

\section{Results}

\section{Distribution of the CD3, CD8, and FOXP3 T lymphocytes among intestinal-type adenocarcinomas and their association with the molecular subtypes}

The number and proportion of T lymphocyte in gastric cancer specimens was assessed using three markers: CD3, marking the entire $\mathrm{T}$ cell population; $\mathrm{CD} 8$, marking the killer/effector $\mathrm{T}$ cells; and FOXP3, marking the regulatory $\mathrm{T}$ lymphocytes (Fig. 1a). Initial analyses were made separately for the $\mathrm{T}$ lymphocyte infiltrates in the invasive front and central area of the tumor. As the results showed no statistical differences between the locations (data not shown), we in subsequent analyses combined results from all four TMA cores of each single tumor. CD3 could be evaluated in $180(n=98 \%), \mathrm{CD} 8$ in 170 
( $n=92 \%)$, and FOXP3 in $173(n=94 \%)$ tumors. The number of infiltrating lymphocytes varied largely between individual tumors, values ranging from 2.9 to $5140.0 / 0.2 \mathrm{~mm}^{2}$ for CD3+ cells, 3.9 to $483.8 / 0.2 \mathrm{~mm}^{2}$ for CD8+ cells, and 0.3 to 178.2 / $0.2 \mathrm{~mm}^{2}$ for FOXP3+ cells (Table 2).

A significantly higher number of infiltrating $\mathrm{T}$ lymphocytes was seen in the EBV-positive tumors in comparison with any other subtype (Fig. 1b-d). This finding was seen for all three $\mathrm{T}$ lymphocyte populations $(\mathrm{CD} 3+, \mathrm{CD} 8+$, and FOXP3+). Between the three other molecular subtypes, no significant differences in the number of $\mathrm{T}$ lymphocytes or the cytotoxic or regulatory subtypes were detected. EBV positivity was also associated with high CD8+/FOXP3+ ratio $(p=$ $0.002)$, whereas the TP53 aberration subtype was associated with low CD $8+/ \mathrm{FOXP} 3+(p<0.0001)$ and $\mathrm{CD} 3+/ \mathrm{FOXP} 3+(p$ $=0.033)$ ratios. The $\mathrm{CD} 3+/ \mathrm{FOXP} 3+$ and $\mathrm{CD} 8+/ \mathrm{FOXP} 3+$ ratio within the different molecular gastric subtypes is shown in Fig. 1e and f, respectively.

For further analyses, the tumors were dichotomized into two categories dependent on whether $\mathrm{T}$ lymphocyte subset values or subset ratios were above or below the median. In these analyses, EBV-positive tumors had higher levels of CD3+ cells $(p=0.002), \mathrm{CD} 8+$ cells $(p=0.001)$, and FOXP3+ cells $(p=0.002)$ as compared with EBV-negative tumors. In addition, $\mathrm{CD} 8+/ \mathrm{FOXP} 3+$ ratio was significantly higher in EBV-positive tumors than in EBV-negative tumors $(p=0.002)$ (Table 3$)$. In contrast, tumors with TP53 aberration were associated with lower number of CD8+ cells $(p=0.02)$ and lower CD8+/FOXP3+ $(p<0.0001)$ and CD3+/FOXP3+ $(p=0.033)$ ratio than the TP53 wild-type tumors. MMR-D tumors did not statistically differ from TP53 aberrant or "other" subtypes, although there was a trend for elevated number of CD8+ cells ( $p=0.096$, Table 2).

\section{CD3+, CD8+, and FOXP3+ T lymphocyte subsets in relation to the clinicopathological characteristics}

Additional comparisons were carried out to find associations between the dichotomized $\mathrm{T}$ lymphocyte subset or subset ratio groups and clinicopathological features. Results on these associations are presented in Table 3.

Above median values of $\mathrm{CD} 3+$ or $\mathrm{CD} 8+\mathrm{T}$ lymphocytes were significantly associated with poor differentiation $(p=$ 0.001 for $\mathrm{CD} 3+, p=0.005$ for CD8+ and $p=0.018$ for CD8/FOXP3 ratio). Tumor localization was associated with the presence of FOXP3+ cells $(p=0.029)$, low numbers of FOXP3 + cells being more common in tumors of the antrum/ pylorus. Male patients had more often tumors with high levels of FOXP3+ lymphocytes $(p=0.025)$. No significant association could be detected between the frequency of CD3+, CD8+ , or FOXP3+ T cells and patient age, tumor size, or tumor location.

\section{CD3+, CD8+, and FOXP3+ cells and other clinical features in relation to survival}

For survival analyses, the gastric cancer tumors were divided into four quartiles depending on the number $\mathrm{CD} 3+, \mathrm{CD} 8+$, and FOXP3+ T lymphocytes. High number of $\mathrm{CD} 3+$ cells was significantly associated with longer recurrence-free

Table 2 The number of lymphocytes in intestinal-type tumors ${ }^{\mathrm{a}}$ and their association ( $p$ value) with different molecular subtypes ${ }^{\mathrm{b}}$

\begin{tabular}{|c|c|c|c|c|c|c|c|c|c|}
\hline & $n$ & Mean & Min & Median & Max & & MMR-D & TP53 aberrant & Other \\
\hline CD3+ & & & & & & CD3+ & & & \\
\hline EBV-positive & 14 & 248.3 & 17.4 & 248.0 & 514.0 & EB-positive & 0.001 & $<0.0001$ & $<0.0001$ \\
\hline MMR-D & 18 & 103.3 & 4.0 & 107.0 & 281.9 & MMR-D & & 0.303 & 0.382 \\
\hline TP53 aberrant & 94 & 87.2 & 2.9 & 68.0 & 397.1 & TP53 aberrant & & & 0.849 \\
\hline Other & 51 & 85.5 & 5.3 & 73.7 & 336.8 & & & & \\
\hline $\mathrm{CD} 8+$ & & & & & & $\mathrm{CD} 8+$ & & & \\
\hline EBV-positive & 14 & 211.4 & 22.4 & 192.9 & 483.8 & EBV-positive & 0.001 & $<0.0001$ & $<0.0001$ \\
\hline MMR-D & 18 & 82.2 & 4.0 & 72.3 & 248.4 & MMR-D & & 0.096 & 0.339 \\
\hline TP53 aberrant & 94 & 55.2 & 3.9 & 41.2 & 325.9 & TP53 aberrant & & & 0.279 \\
\hline Other & 51 & 62.4 & 4.9 & 49.9 & 271.3 & & & & \\
\hline FOXP3+ & & & & & & FOXP3+ & & & \\
\hline EBV-positive & 14 & 61.3 & 9.4 & 54.1 & 137.8 & EBV-positive & 0.002 & $<0.0001$ & $<0.0001$ \\
\hline MMR-D & 18 & 24.0 & 2.0 & 20.0 & 75.0 & MMR-D & & 0.698 & 0.613 \\
\hline TP53 aberrant & 95 & 28.2 & 0.3 & 19.0 & 178.2 & TP53 aberrant & & & 0.150 \\
\hline Other & 51 & 21.3 & 2.3 & 15.0 & 80.6 & & & & \\
\hline
\end{tabular}

${ }^{a}$ Excluding one tumor with negative E-cadherin

${ }^{\mathrm{b}}$ The $p$ values were calculated with Mann-Whitney $U$ test 
a

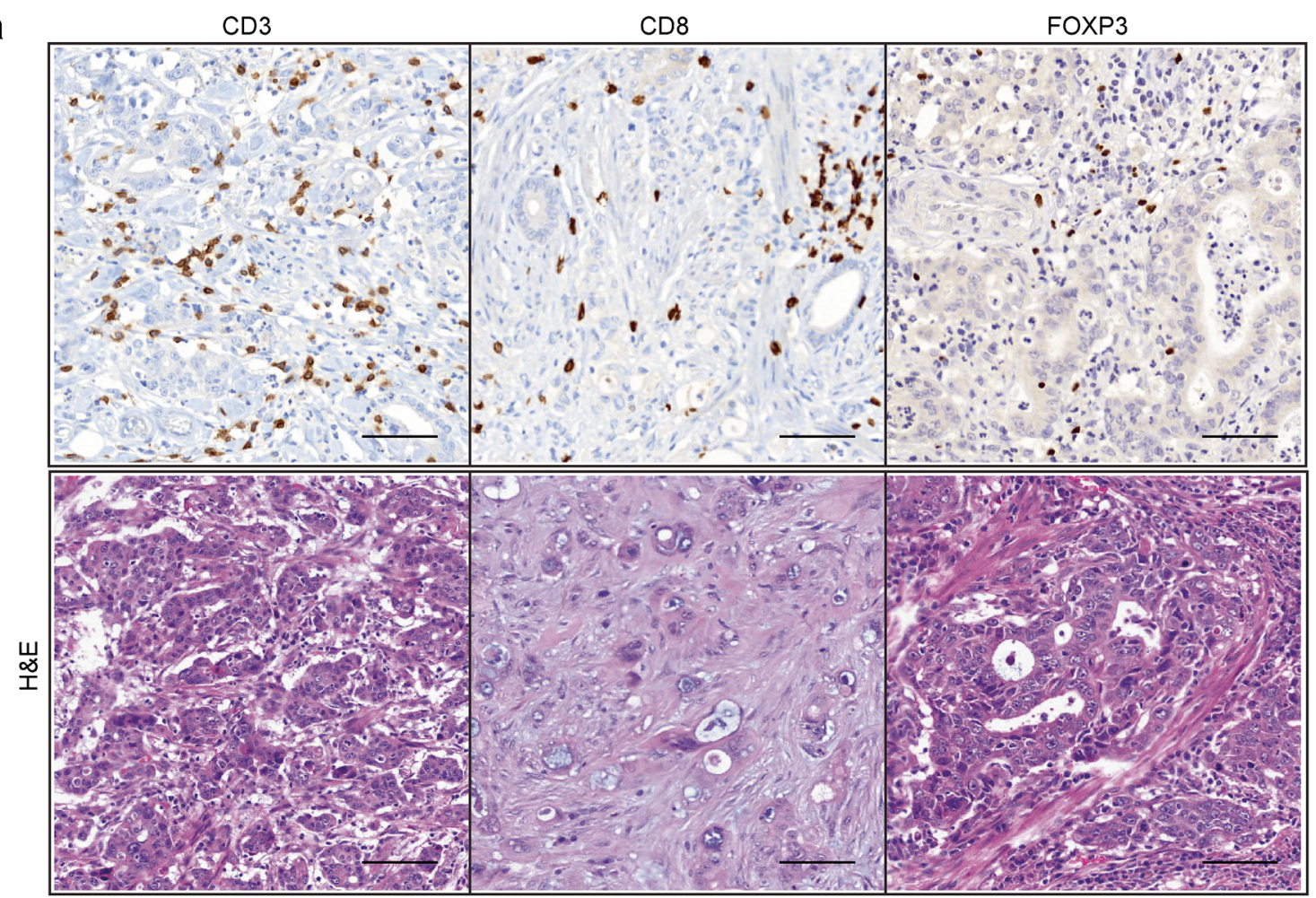

b

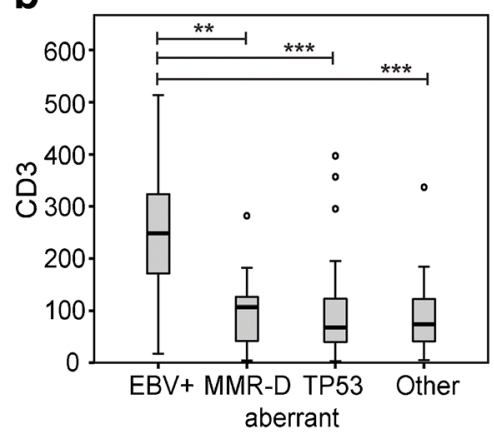

e

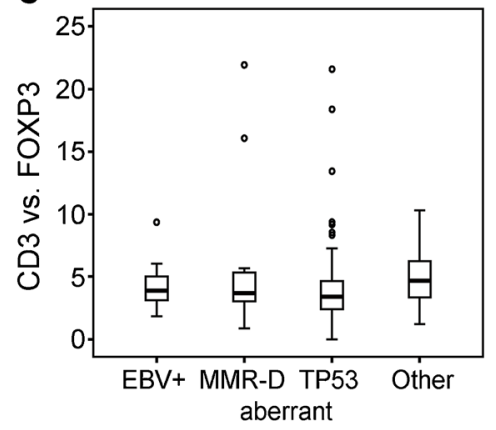

Fig. $1 \mathrm{CD} 3, \mathrm{CD} 8$, and FOXP3 T lymphocytes in four molecular subtypes of intestinal-type gastric adenocarcinoma. a Representative immunohistochemistry images of the different $\mathrm{T}$ lymphocyte subsets and corresponding hematoxylin-eosin images of gastric cancer tumor tissue (from left to right): $\mathrm{CD} 3+\mathrm{T}$ lymphocytes, $\mathrm{CD} 8+$ cytotoxic $\mathrm{T}$ lymphocytes, and FOXP3+ regulatory T lymphocytes. Scale bar $=100 \mu \mathrm{m}$. b-f Box plot d

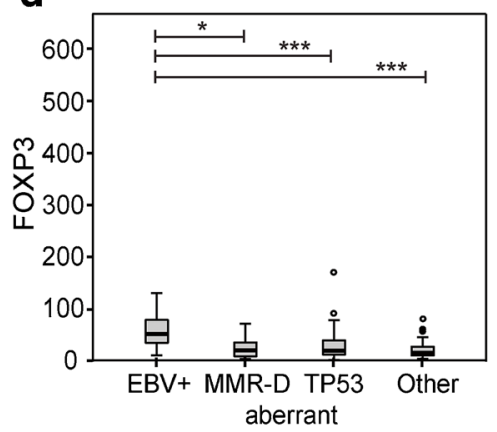

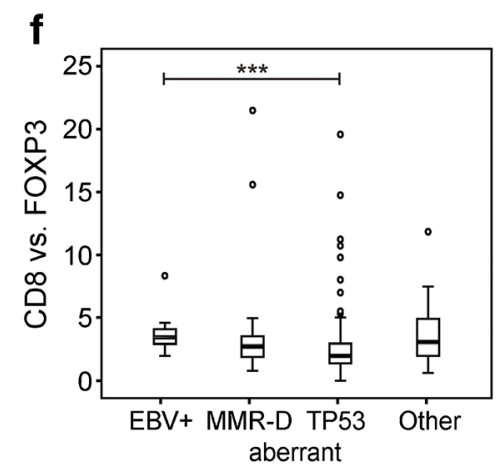

visualization of $\mathrm{T}$ lymphocyte subsets in the different intestinal-type gastric cancer molecular subtypes. b CD3+ T lymphocytes. c. CD8+ T lymphocytes. d FOXP3 + T lymphocytes. e CD3+/FOXP3+ lymphocytes. f CD8+/FOXP3+ lymphocytes. $Y$-axis $=$ number of lymphocytes $/ 0.2 \mathrm{~mm}^{2}$. Outliers are denoted with a circle. ${ }^{*} p=0.002,{ }^{*} p=0.001, * * * p<0.0001$ 


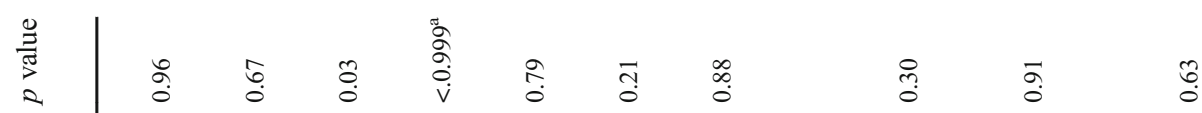

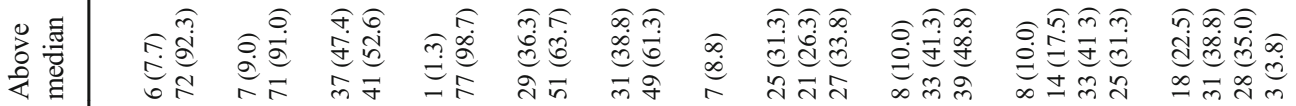
ñ.

空

$\frac{2}{0}$

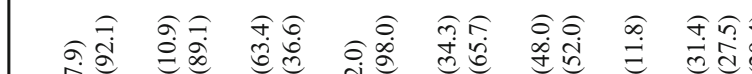

究

$\widehat{\partial} \widehat{ิ}$

กิ $\infty \approx$ 焉 $\hat{x}$

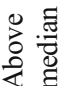

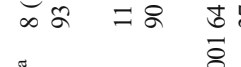

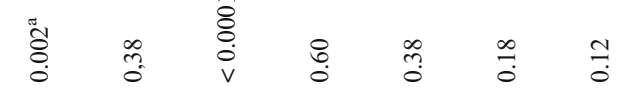

列

$\begin{array}{ll}- & 0 \\ 0 & \stackrel{0}{0}\end{array}$

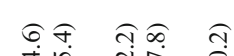

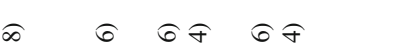

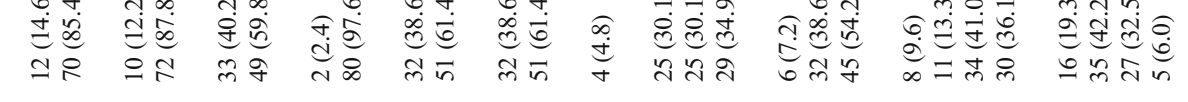

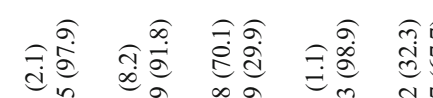

范

\section{สิ ชิ่}

กิิ

ב 6

วิิวิ)

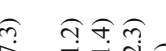

तू $\infty$ ळते चू लॉ

तु

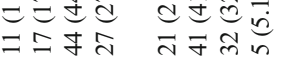

ठี

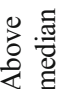

市

ल

$\exists$ in $m= \pm \forall \hat{~}$

$\stackrel{m}{=} \underset{=}{\infty}$

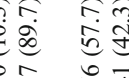

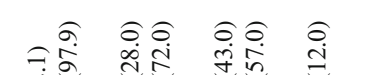

อิ

กิ

ปั่ ปี

సุ

$\because \infty$

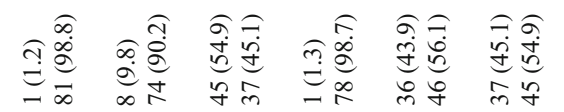

$\stackrel{5}{8}$ ๖. $\stackrel{\circ}{\circ}$

กุ่ s̊.

a

กิ

ç্

วิธ

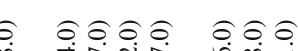

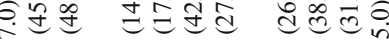

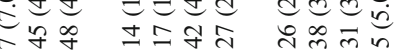

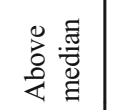

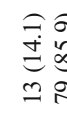

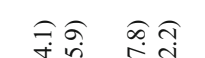

๙ิ)

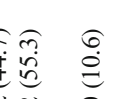

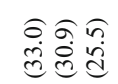

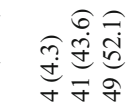

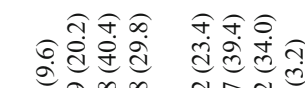

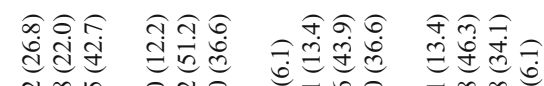

สิ

으궁

in $=0$

$=\underset{\substack{\infty \\ \infty}}{\infty}$

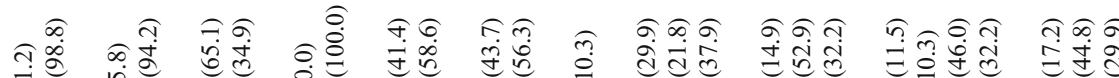

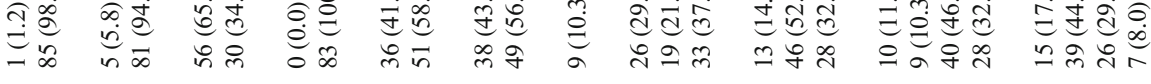

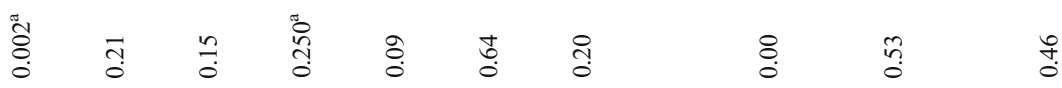
i

尝

कิิ

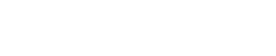

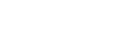

(n)

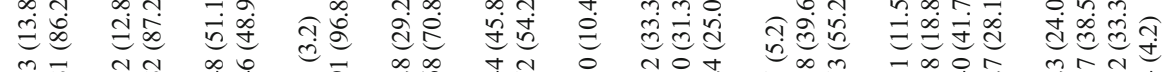

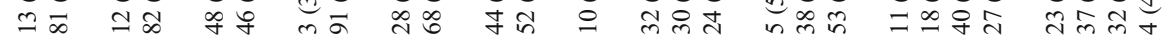

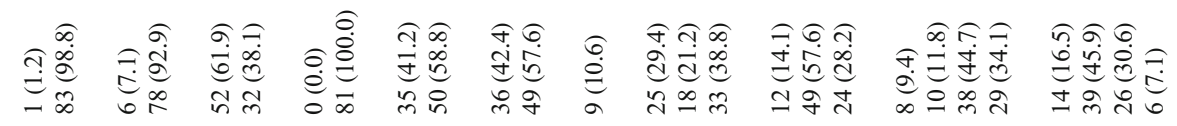

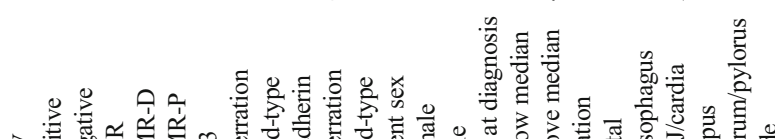

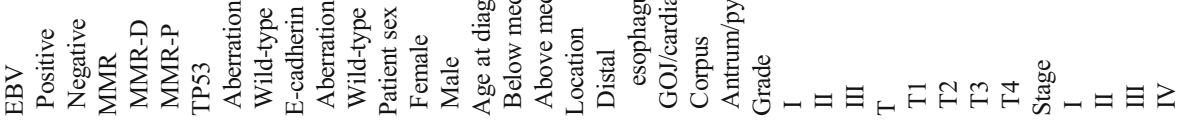



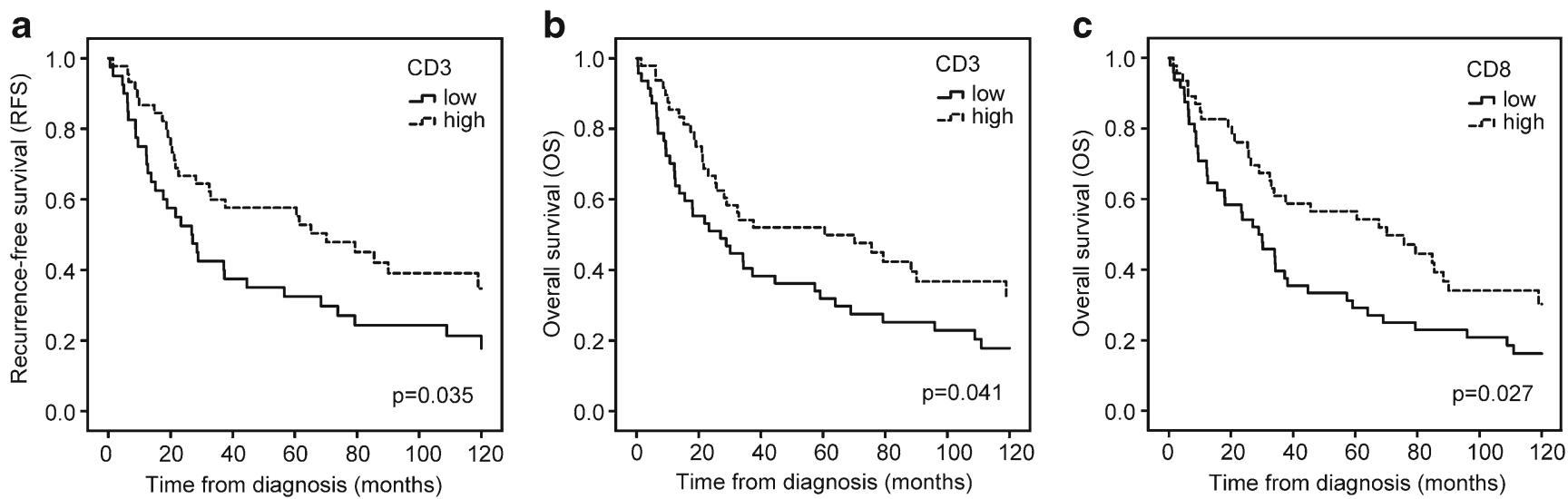

Fig. 2 Kaplan-Meier analysis for recurrence-free survival and overall survival of patients with intestinal-type gastric cancer in relation to T lymphocyte infiltration. a Recurrence-free survival (CD3). b and $\mathbf{c}$ Overall survival (CD3 and CD8, respectively)

survival (log-rank test, $p=0.035$, Fig. 2a). Patients with tumors in the highest quartile of CD3+ (log-rank test, $p=0.041)$ and CD8+ (log-rank test, $p=0.027)$ cells also had significantly higher overall survival than patients with tumors in the lowest quartile of CD3+ and CD8+ cells (Fig. 2b and c, respectively).

In univariate analysis, the highest and lowest quartiles of $\mathrm{CD} 3+, \mathrm{CD} 8+$, and FOXP3+ were associated with RFS and OS. Additional parameters in this comparison were MMR status, tumor size, and stage (Table 4). High amount of CD3+ cells associated with longer RFS (HR 0.58, 95\% CI: 0.35-0.97) and OS (HR 0.61, 95\% CI 0.38-0.98). High amount of CD8+ cells was associated with OS (HR 0.59, 95\% CI: 0.37-0.95) but not with RFS. The amount of FOXP3+ cells did not associate with survival. Patients with MMR-D tumors had longer OS than patients with MMRproficient (MMR-P) tumors. As expected, large tumor size and advanced stage correlated with shorter RFS and OS. The results are shown in Table 4.

In multivariate analysis, high amount of CD3+ cells remained as an independent prognostic factor for longer RFS (HR 0.57, 95\% CI: 0.34-0.96) and OS (HR 00.03, 95\% CI: $00.003-0.31$ ) and high amount of CD8+ cells for OS (HR 17.2, 95\% CI: 1.78-1660.0) (Table 5). Advanced

Table 4 Recurrence-free survival (RFS) and overall survival (OS) of patients with intestinal-type gastric adenocarcinoma

\begin{tabular}{|c|c|c|c|c|c|c|c|c|c|c|c|c|}
\hline & \multicolumn{6}{|c|}{ Univariate survival analysis for RFS } & \multicolumn{6}{|c|}{ Univariate survival analysis for OS } \\
\hline & $\begin{array}{l}\text { Number } \\
\text { of } \\
\text { patients }\end{array}$ & $\begin{array}{l}\text { RFS, } \\
\text { median } \\
\text { (months) }\end{array}$ & $\begin{array}{l}p \text { value } \\
\text { (log-rank } \\
\text { test) }\end{array}$ & $\begin{array}{l}p \text { value } \\
\text { (Cox's } \\
\text { test) }\end{array}$ & HR & $95 \% \mathrm{CI}$ & $\begin{array}{l}\text { Number } \\
\text { of } \\
\text { patients }\end{array}$ & $\begin{array}{l}\text { OS, } \\
\text { median } \\
\text { (months) }\end{array}$ & $\begin{array}{l}p \text { value } \\
\text { (log-rank } \\
\text { test) }\end{array}$ & $\begin{array}{l}p \text { value } \\
\text { (Cox's } \\
\text { test) }\end{array}$ & HR & $95 \% \mathrm{CI}$ \\
\hline \multicolumn{13}{|c|}{ MMR status } \\
\hline MMR-P & 138 & 32.6 & \multirow[t]{2}{*}{0.067} & \multirow[t]{2}{*}{0.072} & \multirow[t]{2}{*}{0.53} & \multirow[t]{2}{*}{$0.27-1.06$} & 161 & 28.7 & \multirow[t]{2}{*}{0.030} & \multirow[t]{2}{*}{0.033} & \multirow[t]{2}{*}{0.48} & \multirow[t]{2}{*}{$0.24-0.94$} \\
\hline MMR-D & 17 & 93.0 & & & & & 17 & 93.0 & & & & \\
\hline \multicolumn{13}{|c|}{$\mathrm{CD} 3$} \\
\hline Q1 & 40 & 26.8 & \multirow[t]{2}{*}{0.036} & \multirow[t]{2}{*}{0.038} & \multirow[t]{2}{*}{0.58} & \multirow[t]{2}{*}{$0.35-0.97$} & 47 & 27.0 & \multirow[t]{2}{*}{0.041} & \multirow[t]{2}{*}{0.043} & \multirow[t]{2}{*}{0.61} & \multirow[t]{2}{*}{$0.38-0.98$} \\
\hline Q3 & 45 & 70.1 & & & & & 48 & 60.5 & & & & \\
\hline \multicolumn{13}{|l|}{$\mathrm{CD} 8$} \\
\hline Q1 & 38 & 28.9 & \multirow[t]{2}{*}{0.065} & \multirow[t]{2}{*}{0.067} & \multirow[t]{2}{*}{0.62} & \multirow[t]{2}{*}{$0.37-1.04$} & 48 & 28.9 & \multirow[t]{2}{*}{0.027} & \multirow[t]{2}{*}{0.028} & \multirow[t]{2}{*}{0.59} & \multirow[t]{2}{*}{$0.37-0.95$} \\
\hline Q3 & 43 & 70.1 & & & & & 46 & 70.1 & & & & \\
\hline \multicolumn{13}{|l|}{ FOXP3 } \\
\hline Q1 & 34 & 26.8 & \multirow[t]{2}{*}{0.050} & 0.053 & 0.61 & $0.37-1.01$ & 36 & 34.2 & 0.247 & 0.249 & 0.75 & $0.47-1.22$ \\
\hline Q4 & 50 & 65.2 & & & & & 56 & 43.4 & & & & \\
\hline $\mathrm{T}$ & & & & & & & & & & & & \\
\hline $\mathrm{T} 1$ & 17 & 65.2 & 0.025 & 0.016 & 1.1 & $1.05-1.58$ & 19 & 32.7 & 0.005 & 0.007 & 1.1 & $1.08-1.57$ \\
\hline $\mathrm{T} 2$ & 26 & 79.3 & & & & & 28 & 70.1 & & & & \\
\hline $\mathrm{T} 3$ & 69 & 30.0 & & & & & 77 & 30.2 & & & & \\
\hline $\mathrm{T} 4$ & 47 & 27.6 & & & & & 58 & 22.9 & & & & \\
\hline Stage & & & & & & & & & & & & \\
\hline I & 36 & 70.1 & 0.042 & 0.012 & 1.1 & $1.07-1.75$ & 39 & 70.1 & $<0.0001$ & $<0.0001$ & 1.1 & $1.24-1.91$ \\
\hline II & 72 & 32.6 & & & & & 75 & 33.8 & & & & \\
\hline III & 51 & 22.6 & & & & & 58 & 22.6 & & & & \\
\hline IV & & & & & & & 10 & 1.9 & & & & \\
\hline
\end{tabular}


Table 5 Multivariate analysis of recurrence-free survival (RFS) and overall survival (OS) of patients with intestinal-type gastric adenocarcinoma Number $\quad p$ value (Cox's test) $\quad$ HR $\quad 95 \%$ CI Number of patients $\quad p$ value (Cox's test) $\quad$ HR $\quad 95 \%$ CI of patients

\begin{tabular}{|c|c|c|c|c|c|c|c|c|c|}
\hline \multicolumn{5}{|c|}{ MMR status } & \multicolumn{5}{|l|}{ MMR status } \\
\hline \multicolumn{5}{|c|}{ MMR-P (ref) } & MMR-P (ref) & 75 & 0.102 & 0.37 & $0.11-1.22$ \\
\hline \multicolumn{5}{|l|}{ MMR-D } & MMR-D & 7 & & & \\
\hline \multicolumn{5}{|l|}{ CD3 } & CD3 & & & & \\
\hline Q1 (ref) & 49 & 0.035 & 0.57 & $0.34-0.96$ & Q1 (ref) & 44 & 0.003 & 0.03 & $0.003-0.31$ \\
\hline Q3 & 48 & & & & Q3 & 38 & & & \\
\hline \multicolumn{5}{|l|}{ CD8 } & CD8 & & & & \\
\hline \multicolumn{5}{|l|}{ Q1 (ref) } & Q1 (ref) & 43 & 0.014 & 17.2 & $1.78-166.0$ \\
\hline \multicolumn{5}{|l|}{ Q3 } & Q3 & 39 & & & \\
\hline \multicolumn{5}{|l|}{ Stage } & Stage & & & & \\
\hline I (ref) & 21 & & & & I (ref) & 17 & & & \\
\hline II & 42 & 0.960 & 0.98 & $0.51-1.91$ & II & 31 & 0.391 & 1.1 & $0.66-2.92$ \\
\hline III & 34 & 0.503 & 1.1 & $0.64-2.51$ & III & 29 & 0.866 & 1.7 & $0.48-2.37$ \\
\hline IV & & & & & IV & 5 & 0.001 & 1.8 & $2.40-28.3$ \\
\hline
\end{tabular}

stage remained as an independent prognostic factor for OS (HR 8.25, 95\% CI: 2.40-28.3). EBV-positive cancers are associated with improved survival as compared with other gastric cancer subtypes [22]. Thus, in our cohort, the association between $\mathrm{CD} 3+$ and CD8+ high tumors and longer RFS and OS could be explained by overrepresentation of EBV-positive tumors in the highest quartile of CD3 and CD8+ cancers. However, when including only the MMR-D, TP53 aberrant, and "other" subtypes, the amount of CD8+ T cells remained significantly associated with OS in univariate (log-rank test, $p$ $=0.043$; Cox test, $p=0.046$; HR 0.58; 95\% CI: 0.34-0.99) and in multivariate analysis (Cox test, $p=0.039$; HR 0.67; 95\% CI: 0.46-0.98).

\section{Discussion}

Host immune response towards cancer varies between cancer types and individuals. The amount of tumor-infiltrating $\mathrm{T}$ lymphocytes has prognostic implications, and may indicate response to immune modulating therapy. While recent studies have shown that intestinal-type gastric cancer consists of several molecular subtypes, the potential of the different subtypes to elicit host immune response is not well-known. Here, we analyzed the presence of intratumoral of $\mathrm{CD} 3+, \mathrm{CD} 8+$, and FOXP3 + T lymphocytes in intestinal gastric cancers representing four different molecular subtypes (EBV, MMRD, TP53 aberrant, and "others"). Our results show that the $\mathrm{EBV}+$ cancers differ from all other subtypes by increased lymphocyte infiltration. While the other subtypes did not differ in the absolute number of T lymphocyte, there was a large variation between individual tumors. Interestingly, the ratio of
FOXP3+ Treg vs. CD3+ or CD8+ cells was highest in the TP53 aberrant subtype, which also has the worst prognosis. The presence of CD3+ and CD8+ T lymphocytes associated with survival in the entire cohort, and in the subset from which the EBV+ tumors were excluded.

The association between a high number of $\mathrm{T}$ lymphocytes and EBV positivity has been previously reported. Ma et al. found that in a cohort of 16, MMR-D, $7 \mathrm{EBV}+$, and 21 nonEBV/MMR-P tumors, MMR-D, and EBV+ subtypes harbored two-fold higher densities of CD8+ T lymphocytes in the invasive part of the tumors [23]. In another set of $20 \mathrm{EBV}+$ and 28 EBV-gastric cancers, Van Beek et al. reported high density of intratumoral lymphocytes, high density of activated granzyme B expressing CD8+ T lymphocytes and a CD8/ CD4 ratio $>1$ in the EBV+ subtype [24]. These studies included relatively small sample numbers from patients of Asian origin. Here, we confirm these results in a larger sample set of intestinal gastric cancers of Caucasian origin.

Previous studies have indicated that MMR-D tumors harbor an increased numbers of T cells. These findings are mostly shown in colorectal and endometrial cancer types, but similar correlation has also been suggested for gastric cancer [25-27]. In our material, the MMR-D tumors did not significantly differ in number of CD3+, CD8+, or FOXP3+ cells from TP53 aberrant and "other" subtypes, although there was a trend towards increased number of CD8+ cells. It is unclear why our results on intestinal-type gastric cancer do not recapitulate the findings from other cancer types. One reason may be the relatively small size of distinct subtypes. It should, however, be noted that results regarding this topic are sparse, and the published gastric cancer studies on the correlation between MMR-D tumors and T lymphocyte counts either lack 
statistical analyses [28], or do not show increased number of T lymphocytes [29]. An exception is the study by Xing et al., which shows an increased number of $\mathrm{CD} 3+$ cells but not CD8+ cells in MMR-D tumors as compared with MMR-P tumors [30]. To conclude, more studies are needed to find out whether MMR-D intestinal gastric cancers have more T lymphocytes than the TP53 aberrant and "other" subtypes."

It has been suggested that cancer cells within MMR-D subtype are able to attract mainly cytotoxic CD8+ T lymphocytes [31]. Recently, immune checkpoint inhibitors have emerged as a new treatment option for certain immunogenic gastric cancers. However, not all patients with $\mathrm{T}$ lymphocyte-inflamed tumors respond to the treatment, indicating that the high number of T lymphocytes is not the only predictor of treatment outcome for MMR-D subtypes but also the complex crosstalk between cancer cells, immune cells, and the tumor microenvironment should be considered [31, 32].

We noticed a decreased ratio of $\mathrm{CD} 3+/ \mathrm{FOXP} 3+$ and CD8+/FOXP3+ cells in the TP53 aberrant tumors when compared with any of the other subtypes. A reduced CD8+/ FOXP3+ ratio has been associated with aggressive nonluminal tumors in breast cancer [33]. In gastric cancer, this is a novel finding and could partly explain the worse prognosis associated with the TP53 subtype. The mutation and chromosomal instability in TP53 subtype in gastric cancer has been suggested as an important biological mechanism driving immunosuppression in the TP53 subtypes [34].

Survival analyses showed a positive association between the amount of CD3+ and CD8+ T cells and increased overall survival. This finding remained significant even when the $\mathrm{EBV}+$ subtype with the highest number of T cells was excluded. This indicates a variation in the host immune response between individuals and a potential prognostic value for $\mathrm{T}$ lymphocyte infiltration in gastric cancer. High expression of CD8+ T lymphocytes had the strongest prognostic association across all four gastric cancer subtypes. Dense intratumoral infiltration of CD3+ T lymphocytes was also significantly associated with longer RFS of the patients, which remained as an independent prognostic factor for longer overall survival in a multivariate analysis. This is in line with a study by Lee et al., where $\mathrm{CD} 3+$ is reported as an independent favorable prognostic factor in gastric cancer [35].

Our study is utilizing a European cohort to investigate the numbers of TILs within four molecular subtypes of intestinaltype gastric cancer. The previous studies have mostly included patients of Asian origin, with somewhat different environmental, lifestyle, and genetic risk factors. Therefore, our study is an important addition to the current knowledge of $\mathrm{T}$ lymphocyte infiltration in intestinal gastric cancer and its prognostic significance.

We conclude that $\mathrm{CD} 3+$ and $\mathrm{CD} 8+$ intratumoral $\mathrm{T}$ lymphocytes are independent prognostic markers, and among all intestinal-type gastric tumors, the EBV+ subtype is the most immunogenic molecular subtype. Better understanding of the role of tumor microenvironment and lymphocyte infiltration in immunogenic gastric cancers could support the treatment decisions when considering immunological therapies for gastric cancer patients.

Authors' contributions Naziha Mansuri, Eva-Maria Birkman, and Olli Carpén conceived and designed the study. Naziha Mansuri wrote the manuscript. Laura Lehtinen and Olli Carpén edited and reviewed it. Eva-Maria Birkman and Jari Sundström identified the patients and reviewed the histology. Annika Ålgars and Raija Ristamäki researched and analyzed patient data. Minnamaija Lintunen processed the IHC analyses. Eva-Maria Birkman carried out statistical analyses. Naziha Mansuri and Vanina D. Heuser scored the IHC results. Olli Carpén takes full responsibility for the work as a whole, including the study design, access to data, and the decision to submit and publish the manuscript. All authors reviewed the manuscript and approved the submitted version.

Funding Open access funding provided by University of Turku (UTU) including Turku University Central Hospital. This work was supported by The Sigrid Jusélius Foundation, Finska Läkaresällskapet, The Finnish Cancer Foundation, and The Cancer Society of South-West Finland

\section{Compliance with ethical standards}

Conflict of interests The authors declare that they have no conflict of interests.

Ethical approval This retrospective study was carried out under the ethical approval for Auria biobank (project number AB14-5616) provided by the National Ethical Committee of Finland TUKIJA according to the Finnish Biobank Act [36].

Open Access This article is licensed under a Creative Commons Attribution 4.0 International License, which permits use, sharing, adaptation, distribution and reproduction in any medium or format, as long as you give appropriate credit to the original author(s) and the source, provide a link to the Creative Commons licence, and indicate if changes were made. The images or other third party material in this article are included in the article's Creative Commons licence, unless indicated otherwise in a credit line to the material. If material is not included in the article's Creative Commons licence and your intended use is not permitted by statutory regulation or exceeds the permitted use, you will need to obtain permission directly from the copyright holder. To view a copy of this licence, visit http://creativecommons.org/licenses/by/4.0/.

\section{References}

1. Ferlay J, Colombet M, Soerjomataram I, Mathers C, Parkin DM, Piñeros M, Znaor A, Bray F (2019) Estimating the global cancer incidence and mortality in 2018: GLOBOCAN sources and methods. Int J Cancer 144:1941-1953. https://doi.org/10.1002/ijc. 31937

2. Ilhan-Mutlu A, Taghizadeh H, Beer A, Dolak W, Ba-Ssalamah A, Schoppmann SF, Hejna M, Birner P, Preusser M (2018) Correlation of trastuzumab-based treatment with clinical characteristics and prognosis in HER2-positive gastric and gastroesophageal junction 
cancer: a retrospective single center analysis. Cancer Biol Ther 19: 169-174. https://doi.org/10.1080/15384047.2017.1414759

3. Bilici A (2014) Treatment options in patients with metastatic gastric cancer: current status and future perspectives. World J Gastroenterol 20:3905-3915. https://doi.org/10.3748/wjg.v20.i14. 3905

4. Kim HJ, Oh SC (2018) Novel systemic therapies for advanced gastric cancer. J Gastric Cancer 8:1-19. https://doi.org/10.5230/ jgc.2018.18.e3

5. Fridman WH, Pagès F, Sauts-Fridman C, Galon J (2012) The immune contexture in human tumours: impact on clinical outcome. Nat Rev Cancer 12:298-306. https://doi.org/10.1038/nrc3245

6. Laurén Pekka. The two histological main types of gastric carcinoma: diffuse and so-called intestinal-type carcinoma. An attempt at a histoclinical classification. Acta Pathol Microbiol Scand 1965;64(1). 10.1111/apm.1965.64.1.31.

7. Bass AJ, Thorsson V, Shmulevich I, Reynolds SM, Miller M, Bernard B et al (2014) Comprehensive molecular characterization of gastric adenocarcinoma. Nature 513:202-209. https://doi.org/10. 1038/nature 13480

8. Birkman E-M, Mansuri N, Kurki S, Ålgars A, Lintunen M, Ristamäki R, Sundström J, Carpén O (2018) Gastric cancer: immunohistochemical classification of molecular subtypes and their association with clinicopathological characteristics. Virchows Arch 472:369-382. https://doi.org/10.1007/s00428-017-2240-x

9. Kang BW, Kim JG, Lee IH, ANS HIB (2017) Clinical significance of tumor-infiltrating lymphocytes for gastric cancer in the era of immunology. World J Gastrointest Oncol 9(7):293-299. https:// doi.org/10.4251/wjgo.v9.i7.293

10. Lee JS, Won HS, Sun DS, Hong JH, Ko YH (2018) Prognostic role of tumor-infiltrating lymphocytes in gastric cancer: a systematic review and meta-analysis. Medicine (Baltimore) 97(32):e11769. https://doi.org/10.1097/MD.0000000000011769

11. Ostroumov D, Fekete-Drimusz N, Saborowski M, Kühnel F, Woller N (2018) CD4 and CD8 T lymphocyte interplay in controlling tumor growth. Cell Mol Life Sci 75:689-713. https://doi.org/ 10.1007/s00018-017-2686-7

12. Zhang L, Xu J, Zhang X, Zhang Y, Wang L, Huang X, Xu Z (2017) The role of tumoral FOXP3 on cell proliferation, migration, and invasion in gastric cancer. Cell Physiol Biochem 42:1739-1754. https://doi.org/10.1159/000479442

13. Bremnes RM, Busund LT, Kilver TL, Andersen S, Richardsen E, Paulsen EE et al (2016) The role of tumor-infiltrating lymphocytes in development, progression, and prognosis of non-small cell lung cancer. J Thorac Oncol 11:789-800. https://doi.org/10.1016/j.jtho. 2016.01.015

14. Jochems C, Schlom J (2011) Tumor-infiltrating immune cells and prognosis: the potential link between conventional cancer therapy and immunity. Exp Biol Med (Maywood). 236(5):567-579. https:// doi.org/10.1258/ebm.2011.011007

15. Santoiemma PP, Powell DJ (2015) 7. Tumor infiltrating lymphocytes in ovarian cancer. Cancer Biol Ther 16:807-820. https://doi. org/10.1080/15384047.2015.1040960

16. Ravelli A, Roviello G, Cretella D et al (2017) Tumor-infiltrating lymphocytes and breast cancer: Beyond the prognostic and predictive utility. 39(4):1010428317695023. https://doi.org/10.1177/ 1010428317695023

17. Domingues B, Lopes J, Soares P, Populo H (2018) Melanoma treatment in review. ImmunoTargets Ther 7:35-49. https://doi. org/10.2147/itt.s134842

18. Nagtegaal ID, Odze RD, Klimstra D, Paradis V, Rugge M, Schirmacher P, Washington KM, Carneiro F, Cree IA, the WHO Classification of Tumours Editorial Board (2020) The 2019 WHO classification of tumours of the digestive system. Histopathology 76:182-188. https://doi.org/10.1111/his.13975
19. Sauerbrei W, Taube SE, McShane LM, Cavenagh MM, Altman DG (2018) Reporting Recommendations for Tumor Marker Prognostic Studies (REMARK): an abridged explanation and elaboration. J Natl Cancer Inst 110:803-811. https://doi.org/10.1093/ jnci/djy088

20. Zlobec I, Suter G, Perren A, Lugli A (2014) A next-generation tissue microarray (ngTMA) protocol for biomarker studies. J Vis Exp:1-9. https://doi.org/10.3791/51893

21. Hanke T, Melling N, Simon R, Sauter G, Bokemeyer C, Lebok P, Terracciano LM, Izbicki JR, Marx AH (2015) High intratumoral $\mathrm{FOXP}^{+} \mathrm{T}$ regulatory cell (Tregs) density is an independent good prognosticator in nodal negative colorectal cancer. Int J Clin Exp Pathol. 8(7):8227-8235

22. Kyoung-Mee Kim, Alejandro H Corvalan, Keitaro Matsuo, Jun Yu, Joseph J Y Sung, Roberto Herrera-Goepfert, Fernando MenesesGonzalez, Yuko Kijima, Shoji Natsugoe, Linda M Liao, Jolanta Lissowska, Sung Kim, Nan Hu, Carlos A Gonzalez, Yashushi Yatabe, Chihaya and CSR. Improved survival of gastric cancer with tumour Epstein-Barr virus positivity: an international pooled analysis. Gut 2014;63:236-243. https://doi.org/10.1136/gutjnl-2013304531 .

23. Ma C, Patel K, Singhi AD, Ren B, Zhu B, Shaikh F, Sun W (2016) Programmed death-ligand 1 expression is common in gastric cancer associated with Epstein-Barr virus or microsatellite instability. Am J Surg Pathol 40:1496-1506. https://doi.org/10.1097/PAS. 0000000000000698

24. Van Beek J, Zur Hausen A, Snel SN, Berkhof J, Kranenbarg EK, Van De Velde CJH et al (2006) Morphological evidence of an activated cytotoxic T-cell infiltrate in EBV-positive gastric carcinoma preventing lymph node metastases. Am J Surg Pathol 30:59-65. https://doi.org/10.1097/01.pas.0000176428.06629.1e

25. Narayanan S, Kawaguchi T, Peng X, Qi Q, Liu S, Yan L, Takabe K (2019) Tumor infiltrating lymphocytes and macrophages improve survival in microsatellite unstable colorectal cancer. Sci Rep 9:110. https://doi.org/10.1038/s41598-019-49878-4

26. Eggink FA, Van Gool IC, Leary A, Pollock PM, Crosbie EJ, Mileshkin L, Jordanova ES, Adam J, Freeman-Mills L, Church DN, Creutzberg CL, De Bruyn M, Nijman HW, Bosse T (2016) Immunological profiling of molecularly classified high-risk endometrial cancers identifies POLE-mutant and microsatellite unstable carcinomas as candidates for checkpoint inhibition. Oncoimmunology 6(2):e1264565. https://doi.org/10.1080/ 2162402X.2016.1264565

27. Ratti M, Lampis A, Hahne JC, Passalacqua R, Valeri N (2018) Microsatellite instability in gastric cancer: molecular bases, clinical perspectives, and new treatment approaches. Cell Mol Life Sci 75: 4151-4162. https://doi.org/10.1007/s00018-018-2906-9

28. Cho J, Chang YH, Heo YJ, Kim S, Kim NKD, Park JO, Kang WK, Lee J, Kim KM (2018) Four distinct immune microenvironment subtypes in gastric adenocarcinoma with special reference to microsatellite instability. ESMO Open 3:1-9. https://doi.org/10.1136/ esmoopen-2018-000326

29. Challoner BR, von Loga K, Woolston A, Griffiths B, Sivamanoharan N, Semiannikova M, Newey A, Barber LJ, Mansfield D, Hewitt LC, Saito Y, Davarzani N, Starling N, Melcher A, Grabsch HI, Gerlinger M (2020) Computational image analysis of T-cell infiltrates in resectable gastric cancer: association with survival and molecular subtypes. Journal of the National Cancer Institute; djaa051. Advance online publication. https:// doi.org/10.1093/jnci/djaa051

30. Xing X, Guo J, Ding G, Li B, Dong B, Feng Q, Li S, Zhang J, Ying X, Cheng X, Guo T, du H, Hu Y, Zhou T, Wang X, Li L, Li Q, Xie M, Li L, Gao X, Shan F, Li Z, Jia S, Wen X, Wang J, Ji J (2018) Analysis of PD1, PDL1, PDL2 expression and T cells infiltration in 1014 gastric cancer patients. Oncoimmunology 7:e1356144. https://doi.org/10.1080/2162402X.2017.1356144 
31. Chiaravalli AM, Klersy C, Vanoli A, Ferretti A, Capella C, Solcia E (2012) Histotype-based prognostic classification of gastric cancer. World J Gastroenterol 18:896-904. https://doi.org/10.3748/wjg. v18.i9.896

32. Kim ST, Cristescu R, Bass AJ, Kim KM, Odegaard JI, Kim K, Liu XQ, Sher X, Jung H, Lee M, Lee S, Park SH, Park JO, Park YS, Lim HY, Lee H, Choi M, Talasaz AA, Kang PS, Cheng J, Loboda A, Lee J, Kang WK (2018) Comprehensive molecular characterization of clinical responses to PD-1 inhibition in metastatic gastric cancer. Nat Med 24:1449-1458. https://doi.org/10.1038/s41591018-0101-Z

33. Liu F, Lang R, Zhao J, Zhang X, Pringle GA, Fan Y, Yin D, Gu F, Yao Z, Fu L (2011) CD8+ cytotoxic T cell and FOXP3+ regulatory $T$ cell infiltration in relation to breast cancer survival and molecular subtypes. Breast Cancer Res Treat. 130(2):645-655. https://doi.org/ 10.1007/s10549-011-1647-3
34. Jiang Z, Liu Z, Li M, Chen C, Wang X (2018) Immunogenomics analysis reveals that TP53 mutations inhibit tumor immunity in gastric cancer. Transl Oncol 11:1171-1187. https://doi.org/10. 1016/j.tranon.2018.07.012

35. Lee HE, Chae SW, Lee YJ, Kim MA, Lee HS, Lee BL, Kim WH (2008) Prognostic implications of type and density of tumourinfiltrating lymphocytes in gastric cancer. Br J Cancer 99:17041711. https://doi.org/10.1038/sj.bjc.6604738

36. Finlex Data Bank. https://www.finlex.fi/fi/laki/kaannokset/2012/ en20120688.pdf. Accessed 23 April 2012017

Publisher's note Springer Nature remains neutral with regard to jurisdictional claims in published maps and institutional affiliations. 